\title{
ROLE PLAY PARA GRADUANDOS E O ENSINO DA LEITURA
}

\author{
Marizete Righi Cechin
}

\section{ROLE PLAY E SUA IMPORTÂNCIA PEDAGÓGICA}

Conheci o Role Play em 1996, quando buscava uma opção de trabalho pedagógico para o ensino de língua portuguesa que valorizasse a interatividade dos alunos usando simulações com exigências verossímeis. As conversas informais com o Professor Dr. Marcos Gustavo Richter (UFSM) possibilitaram a aplicabilidade da técnica para alunos do ensino médio. Logo, o Prof. Marcos e eu organizamos uma oficina para professores no Seminário Novas Propostas para o Desenvolvimento da Linguagem, que exigia dos participantes o compromisso em elaborar perfis e viver os personagens elaborados. O resultado da oficina ficou registrado no livro Ensino do Português e Interatividade (Richter, 2000), publicado pela Editora da UFSM. Depois disso, comecei a usar o jogo nas aulas para graduandos. Os resultados mostravam-se promissores e de grande poder de reflexão; entretanto não publiquei artigo algum sobre tais experiências. Este ano, o jogo de papéis foi usado para facilitar a compreensão do livro Quem mexeu no meu queijo? - e a experiência foi excelente. A motivação, a criatividade e as transformações que os alunos viveram em função da atividade mostram a necessidade de compartilhá-la.

O nome Role Play pode ser entendido como "jogo de papéis". A princípio pode parecer estranho um jogo em que as pessoas assumem papéis e brincam com isso, mas se o passado for retomado, percebe-se que as afinidades entre este jogo e as brincadeiras infantis são maiores do que se imagina. Na infância, quando a menina brinca de ser mãe ${ }^{[1]}$, por exemplo, antes de brincar observa as mães que conhece, traça um perfil para o papel de mãe, assume o perfil e só depois é que vai brincar de ser mãe. Quando um garotinho brinca de ser cantor, ele também faz o mesmo processo que a menina fez para brincar de ser mãe, ou seja, observa o perfil do personagem que deseja encenar, traça mentalmente o perfil, assume o perfil e encena. Assim, o ato de encenar papéis é familiar a todo o ser humano. Quando o menino e a menina crescem, continuam fazendo a mesma dinâmica. O adolescente e o adulto precisam da "ficção para alimentar o imaginário, aliviar tensões, encontrar respostas às dúvidas, viver experiências impossíveis de serem vividas no mundo real, rompendo com os limites do tempo e do espaço" Higuchi \& Roberti (2000, p:182). Usar a sala de aula como palco para que os educandos aprimorem conhecimentos através do assumir papéis (lê-se situações) que talvez não houvessem vivenciado, possibilita que esses educandos sintam as emoções similares a tal situação, como se ela fosse real.

Higuchi \& Roberti (2000, p:201-2) afirmam que, em termos de sala de aula,

à medida que as crianças, com idades variadas e diversos níveis de aprendizagem, participam dessas atividades [assumirem papéis], 
fora da sala de aula, aumentam a sociabilidade, conversam de forma mais interativa, desenvolvem o raciocínio, a noção espacial e temporal, enriquecem o vocabulário, escrevem com mais espontaneidade.

Essa afirmação também é válida para o público adulto, pois as observações e os depoimentos dos acadêmicos revelam transformações significativas no agir e pensar.

\section{A RELAÇÃO DE ROLE PLAY COM ROLE PLAYING GAME}

Ao ouvir Role Play (RP), o leitor pode relacioná-lo ao Role Playing Game - RPG, aquele jogo em que os participantes assumem papéis e brincam durante horas. Esta relação é possível, pois há semelhanças entre eles.

O RPG - Jogo de Interpretações de Papéis (JIP) - nasceu nos Estados Unidos em 1974[2], "como um meio-termo entre jogos de guerra altamente especializados e jogos familiares simples, destacando-se pela arte de contar e participar de histórias" Higuchi \& Roberti (2000, p:178). O RPG é um jogo em que os participantes assumem papéis com perfis de personagem já traçados. Pode-se criar os personagens e os perfis, como se pode assumir papéis indicados em livros de RPG. A princípio os livros traziam ambientação medieval; atualmente a ambientação é bastante variada, mais isso não altera a interpretação do papel, o importante é a transferência mental e linguística dos personagens para o universo ficcional da narrativa.

No Brasil, o RPG chegou na década de 80, o primeiro livro aqui foi Dungeons \& Dragons (D\&D) [3]. Logo vieram outros influenciados especialmente pela mitologia de O Senhor dos Anéis, de J. R. R. Tolkien. Atualmente, o RPG já pode ser encontrado em programas de computador, como os jogos Wizardry e Ultima. Existem três tipos de RPG:

O de mesa, com livros e regras, onde um grupo de RPG se reúne em torno de uma mesa e joga com tabuleiros, seguindo todas as regras dadas nos livros básicos; o live action, com regras mais flexíveis, que dá ênfase à interpretação, onde os jogadores interpretam o personagem realmente, usando fantasias, ou seja, vestindo-se da mesma forma que ele, falando do jeito dele, enfim, sendo ele; e o mais recente PBEM[4], ou Play By Email, que traduzido seria "jogo por email", nascido junto com a internet, possibilita jogadores que não tenham acesso ou não possam formar um grupo, jogar com integrantes em qualquer parte do mundo que esteja conectado à internet (p:01. RPG. http://amalgama.hpcorp.com.br/rpg.htm)

Para se jogar RPG, é necessário uma aventura, perfis de personagens, conjunto de 6 dados (com 4, 6, 8, 10, 12 e 20 lados), opcionalmente roupas especiais e adereços. O jogo se dá em grupo, um dos integrantes é o mestre e os outros são os atores. É interessante destacar que a ação toda acontece apenas verbalmente e na imaginação dos jogadores. 
O RPG, de certa forma, converte-se em um tipo de Role Play ao ser usado em sala de aula. Em contexto didático, a aventura do RPG antes descrita em livros próprios para o jogo se transforma numa encenação no RP, com um tema ou uma situação discutidos no grupo. Os perfis dos personagens do RPG geralmente estão descritos nos livros; no RP, esses perfis são traçados a partir do que o grupo decidir. Assim, pode-se interpretar perfis de personagens da mídia televisiva ou de obras literárias, por exemplo, ou, ainda, estes podem ser construídos através do conhecimento de mundo dos jogadores. Outra adequação é o não uso dos dados, pois em RPG os dados são usados para decidir o destino dos participantes, seguindo instruções do livro. As roupas especiais e adereços, opcionais em RPG, geralmente assumem maior relevância no RP na medida em que os alunos tenham preocupações de representar os personagens de modo mais completo. Desse modo, é comum o uso de roupas e adereços que caracterizem os personagens encenados. Quanto ao uso de um único mestre no RPG, em sala de aula isso é raro; todos são mestres, pois o enredo é feito no coletivo.

Entre as principais vantagens do RP cita-se: 1) a de se trabalhar exercícios de conversação em variadas situações, 2) a de se construir habilidades lingüísticas que o currículo não oferta, 3) a de se promover a desinibição dos educandos através da interpretação de papéis (o educando começa a perder o medo de se mostrar porque na interpretação de papéis ele não está representando a si, mas a personagem), 4) a de ser divertido; e 5) "o role play é toda uma escala de técnicas comunicativas que desenvolve a fluência na linguagem dos estudantes, que promove a interação em sala de aula e desenvolve a motivação"[5] (Ladousse, 1988, p:7)

\section{A EXPERIÊNCIA COM RP PARA GRADUANDOS}

A experiência com RP que segue aconteceu em Pato Branco/PR, na Faculdade de Pato Branco/FADEP, em junho de 2002. Lá, trabalho com a disciplina Comunicação Empresarial I, que faz parte da grade curricular do primeiro período do curso de administração Geral, Rural e Gestão da Informação. Os acadêmicos que freqüentam a disciplina são da cidade de Pato Branco e da região. Há um público variado que vai desde o adolescente que está na sala de aula sem saber o porque (ou melhor, ele sabe que está lá porque o pai quer) e o adulto maduro, com família constituída e com alguns anos de experiência profissional.

Essa disciplina tem um foco bem delimitado: trabalhar com a leitura proveitosa. Esclarece-se que se entende por este tipo de leitura aquela em que o leitor, depois de ler, entende o que leu a ponto de reproduzir o texto com suas palavras. Ensinar a ler com eficiência num espaço com tanta diversidade de geração e com uma média de 50 alunos por sala é um grande desafio. Desafio maior é fazer com que essa leitura seja prazerosa. Não se pode esquecer que as aulas são à noite, e muitos dos alunos chegam cansados da jornada de trabalho.

Entre as variadas estratégias de leituras que possam dar prazer, a diversidade de materiais é uma estratégia que gosto de usar e acredito ser útil para a realidade que tenho. Assim, surgiu a possibilidade de trabalhar com a obra Quem mexeu no 
meu queijo?, de Spencer Johnson. Quando a li, a Revista Exame (edição 766, p:78) a classificava como a obra destaque de 2001, afirmando:

"o mercado editorial se volta para as inseguranças geradas por um turbilhão de transformações. Lançado em 1998, Quem mexeu no meu queijo?, livro do médico americano Spencer Johnson sobre como lidar com tantas mudanças, já vendeu mais de 10 milhões de exemplares em 11 idiomas"

Logo, a Revista Veja (edição 1756, p:133) classificava a obra como a mais vendida (primeiro lugar) e informava que era a $79^{a}$ semana consecutiva na lista dos dez livros de auto-ajuda e esoterismo mais vendidos no Brasil[6]. Comentei com os alunos o enredo da obra e questionei a possibilidade de usá-la na aula. Marcamos uma data para que todos pudessem adquirir a obra e dar início à leitura.

Geralmente a leitura de materiais longos é feita extra-sala, mas esta obra precisava ser lida em sala de aula. Acreditava que a leitura levaria 4 horas/aula, que não seria cansativa e que seria importante eu verificar as reações dos acadêmicos à medida que fossem lendo. Toda a obra foi lida em voz alta, cada página era lida por um educando (aproveitei para ouvir a voz dos mais tímidos depois, alguns alunos comentaram que foi importante terem tomado coragem e lido em voz alta para todos, e também que foi menos difícil do que pensavam).

O enredo do livro é simples. Um grupo de estudantes encontra-se depois de terem estudado juntos e percebem que os planos profissionais feitos na época do colegial não aconteceram. Tentam entender o porquê da não-concretização dos planos, quando descobrem que o que houve foi que o mundo estava em transformação e os planos não, estes continuavam estagnados em um tempo passado. Além de os planos estarem numa época que não existia, os próprios estudantes estavam resistentes às mudanças e não flexíveis às transformações. $A$ percepção dessa inflexibilidade à mudança se dá quando a história de Quem mexeu no meu queijo? é contada. Nela há dois ratos e dois gnomos. Os ratos são Sniff e Scurrys e os duendes são Hem e Ham. As características desses quatro personagens contemplam fases diferentes dos modos como se pode ver as transformações e agir (ou reagir) a elas. Assim, cada um dos quatro personagens do livro representa um pouco do que o ser humano pode ser no seu viver:

"às vezes podemos agir como Sniff que percebe a mudança logo, ou Scurry que sai correndo em atividade, ou Hem que rejeita a mudança, resistindo-Ihe, assim como teme que ela leve a algo pior, ou Ham que aprende a se adaptar a tempo, quando percebe que a mudança leva a alguma coisa melhor." (Johnson, 2002, p:10).

Percebi que a leitura da obra havia mexido com os educandos, não só pelos comentários feitos durante a leitura oral (parávamos de tempo em tempo para conversarmos sobre o lido), mas também pelo silêncio introspectivo que observava quando estávamos lendo. Pensei que deveria usar aquela obra para 
jogar RP e deixar o livro mais bem compreendido. Fiz, então, vários cartões, cada um com um nome dos quatro personagens da história, Sniff, Scurry, Hem e Haw. Pedi que os alunos montassem grupos por afinidade (optei por este critério de montagem de grupo pela necessidade de os elementos terem certa intimidade e familiaridade entre si para negociar situações). Depois, cada integrante do grupo pegou um cartão. O nome do personagem lhe atribuía a personalidade na encenação. Cada grupo precisava criar uma situação empresarial com começo, meio e fim em que estivessem envolvidos tantos personagens variados quantos o grupo havia pegado. Além disso, cada grupo precisava entregar por escrito, no dia da apresentação, o enredo. A princípio, alguns grupos relutaram - afinal, teriam que construir por si uma história com as condições que os personagens lhes atribuíam - mas depois começaram a negociar. A apresentação foi realizada no anfiteatro da faculdade. Paralelamente contatei o pessoal de recursos audiovisuais para filmar as apresentações, proporcionando registros e tirei algumas fotos em uma máquina fotográfica digital. O uso desses materiais deixou os grupos mais empolgados.

A diversidade de situações criadas a partir dos personagens do livro Quem mexeu no meu queijo? foi uma marca nas três turmas. Os acadêmicos assimilaram os papéis dos personagens do livro de modo impressionante. Para ilustrar, passo a expor um dos enredos criados. O grupo organizou o palco do anfiteatro com mesas e cadeiras para funcionar como uma imagem de escritório. Lá, funcionava uma firma que havia mudado o uniforme dos funcionários. Os homens mantinham a tradicional maneira de se vestirem, mas as mulheres precisavam adotar o uso de saias pretas. De acordo com os perfis das personagens, as reações foram variadas. Com exceção de uma funcionária, as outras, assim que receberam o novo uniforme, passaram a usá-lo, embora comentassem o desconforto das saias. A única funcionária que resistia ao novo uniforme (a de perfil do personagem Haw) insistia em ir trabalhar com o antigo uniforme, aquele que tinha calça com casaco. Enquanto a peça transcorre no palco, a tal funcionária vai percebendo que a mudança é necessária, e se não se adaptar, o emprego não mais será dela. A maneira como esta personagem vai enfrentando as dificuldades de se adaptar às mudanças faz com que, facilmente, o público relacione a peça com a vida particular, quando, em situações simples, há uma enorme resistência ao novo.

Ainda um outro exemplo. O cenário foi montado como sendo uma rua com lojas. Para decorar as lojas, os acadêmicos negociaram com os lojistas da cidade. Em troca dos empréstimos dos produtos, eles anunciaram o nome das lojas. Assim, a peça começa com um lojista vendendo lingerie. Um grupo de meninas entra no estabelecimento e logo percebem a inadequação dos modelos: só há ceroulas, calcinhas tradicionais e enormes sutiãs. Percebendo a não concorrência, o grupo de meninas monta uma loja de lingerie onde se tem variedade de cor e modelos. A dupla da primeira loja não percebe de imediato as transformações que ocorrem no mundo da moda e nos desejos dos consumidores. Os clientes desaparecem, a justificativa para o sumiço deles é a crise do país. Um dos vendedores (o e perfil semelhante ao personagem Haw) começa a perceber que precisa mudar. Quebra a sociedade da loja e vai investigar onde e como poderá atuar no mercado. Abre o primeiro sex shop da cidade. Enquanto a cena se passa, é notável a curiosidade do público em ver tantos objetos eróticos que antes só ficavam na imaginação. O 
próprio grupo comentou o desafio de levar tais peças para o palco e tocá-las com naturalidade como se fosse natural o manuseio.

Como se percebe, os perfis dos personagens da obra Quem mexeu no meu queijo? foram interpretados e adequados à realidade empresarial de um modo bastante criativo. Os acadêmicos estavam visivelmente empolgados com 0 resultado obtido. Além disso, é importante ressaltar que eles tiveram de resgatar algumas partes do livro para adequar as ações dos personagens da interpretação às dos personagens da obra, o que provocou uma releitura do livro.

\section{RESULTADOS: ALGUMAS TRANSFORMAÇÕES NOS EDUCANDOS}

Depois que as ações aconteceram, fez-se uma discussão sobre o ocorrido. Percebi que os depoimentos eram muito ricos e foram necessários registros. Marcamos uma data para uma avaliação e auto-avaliação, aproveitei para entregar junto uma folha com uma questão (sem influência na quantificação da avaliação) para que opinassem sobre a forma como a disciplina era conduzida. $O$ que segue são fragmentos do que foi escrito nessa página complementar à avaliação.

Uma das ações mais comentadas foi a leitura do livro Quem mexeu no queijo? e o RP feito a partir dele. É interessante destacar que os alunos não conhecem o conceito de RP, nem comentei com eles o nome da ação que estavam desenvolvendo. Assim, os graduandos chamaram o RP de "teatro". Vamos ao primeiro depoimento:

"Uma das aulas e métodos mais produtivos na minha opinião foi a
leitura do livro "Quem mexeu no meu queijo?, onde após a leitura
tivemos que fazer um pequeno teatro, isso fez com que pudéssemos
relacionar o livro ao nosso cotidiano, ajudando a compreender
melhor as mudanças e encará-las melhor".[7] (aluna T de
Administração Geral)

Nota-se no comentário que a aplicabilidade da obra no quotidiano se deu em função do RP. Também é perceptível a relevância da tarefa para a aluna, quando comenta que a obra foi importante para encarar e compreender as mudanças quotidianas.

\footnotetext{
"Eu achei legal o texto Quem mexeu no meu queijo?, porque, além de nos trazer uma lição de vida, tivemos que fazer o teatro, que foi produtivo no meu ponto de vista, porque fomos no palco e perdemos o medo" (aluna AN de Administração Rural).
}

O comentário "legal" refere-se ao fato de a aluna perder o medo de ir ao palco. "O Role Play ...leva os alunos a se "soltarem" na classe, perdendo a inibição e se tornando mais comunicativos e participantes - mais sujeitos do processo..." (Richter, 2000, p: 121-2). O registro é compartilhado por outros alunos, que similarmente tinham medo de aparecer para os colegas e o fato do RP proporcionar essa aparição de modo agradável provocou a sensação de poder e 
vitória, pois o palco para muitos parecia um lugar assustador.

"Achei extremamente produtivo o teatro realizado após a leitura do livro "Quem mexeu no meu queijo?", ajudou-me muito em meu trabalho de TGA e na minha vida particular. Foi um espetáculo, tornou o livro muito mais marcante e aguçou nossa criatividade" (aluna AD de Administração Geral)

O comentário afirma que a acadêmica usou os conhecimentos da aula de Comunicação Empresarial na aula de Teoria Geral de Administração (TGA). Isso mostra a interatividade da ação que a educanda fez. Além disso, destacou a criatividade, característica do RP, pois nele o aluno é sujeito do processo e não mero executor de tarefas com respostas prontas. Richter (2000, p:121) chama a atenção para o Role Play por ele valorizar o educando e ir em direção oposta à do ensino tradicional, pois este "habitua os alunos a um papel passivo, de meros receptores de informação que já devem vir prontas para absorção sem esforço intelectual", enquanto aquele tem um ensino interativo, em que o aluno é sujeito do seu processo e a informação está para ser pesquisada e elaborada pelo grupo.

“... estou mais comunicativa com as aulas de Comunicação Empresarial I, meu vocabulário mudou, algumas atitudes foram mudadas e o motivo da mudança foi o nosso teatro, notei que me soltei mais e que estou crescendo muito mais como pessoa, também em debates em sala de aula, me ajudou a me soltar mais porque antes eu era muito tímida e também estou aprendendo a gostar mais de leitura o que antes não era o meu hábito." (aluna L de Administração Gestão)

O depoimento desta aluna reflete a percepção da acadêmica quanto às mudanças que ela percebeu. O fato de estar mais comunicativa e de mudar o vocabulário é atribuído ao Role Play. Essas características do RP já foram destacadas por Ladousse (1998) quando pontua as vantagens do jogo de papéis em sala de aula. Além dessas transformações, a estudante destaca outra conseqüência provocada pelo uso do RP, o despertar para a leitura. Esse depoimento é compartilhado com outros educandos, entre eles:

“... comecei a ler com mais vontade depois que lemos em grupo o livro "Quem mexeu no queijo?", ele me inspirou, aliás, quando acabamos de estudá-lo dei para minha mãe ler e ela adorou." (aluno MA de Administração Gestão)

“... como dizia antes, não tinha o costume de ler, agora até estou impressionada comigo mesma, troco a TV para ler uma revista "Superinteressante"' (aluna L de Administração Geral)

“... posso citar que meu interesse pela leitura também melhorou, pois nunca me imaginava lendo um livro de 800 páginas e lá estou e não consigo deixar de lê-lo nas horas vagas" (aluno $W$ de Administração Gestão) 
"... uma coisa que aprendi e fiquei feliz foi que reaprendi a ler. Antes lia sempre com voz alta e não conseguia me concentrar se não fosse assim, hoje leio com facilidade só com os olhos e consigo absorver as idéias." (aluna A de Administração Geral)

Nota-se com estes depoimentos os resultados positivos que a realização do Role Play proporcionou aos educandos. Destaco que o desafio de tornar a leitura prazerosa parece ter sido vencido, pois as transformações descritas são indícios de que os alunos perceberam que a leitura pode ser atrativa e envolvente. Além disso, pode-se dizer que a leitura da obra Quem mexeu no meu queijo? desencadeou discussões e interpretação além da sala de aula, conforme registros dos alunos, envolvendo a família, os amigos e o espaço profissional. Tudo isso reforça a tese de que o uso de Role Play é uma alternativa eficiente e de resultados significativos no ensino superior.

\section{BIBLIOGRAFIA}

HIGUCHI, Kazuco Kojima \& ROBERTI, Glauco Micsik. RPG: o resgate da história e do narrador. In:Outras linguagens na escola: publicidade, cinema e tv, rádio, jogos, informática. São Paulo: Cortez, 2000. p.175-211.

JOHNSON, Spencer. Quem mexeu no meu queijo? ed. 31 Rio de Janeiro: Record, 2002.

LADOUSSE, Gilian Porter. Role Play. Oxford: Oxford University Press, 1988.

Revista Exame. Idéia, evoluções, revoluções. 15 de maio de 2002, edição 766, ano $36, n^{0} 10$, p.74-78.

Revista Veja. Os mais vendidos. 19 de junho de 2002, edição 1756 , ano 35, $\mathrm{n}^{0}$ 24, p.133.

RICHTER, Marcos Gustavo. Ensino do português e interatividade. Santa Maria: UFSM, 2000.

RPG. http://amalgama.hpcorp.com.br/rpg.htm. Acessado em 09/08/02.

[1] Considera-se apenas a brincadeira em si, não a ideologia que está por trás do papel de mulher que a menina representa.

[2] Há quem diga que o RPG foi inventado em 1965 por Dave Anerson, nos Estados Unidos (O altar do RPG. http://urbanoide.cidadeinternet.com.br/canais/reverbo/altar_do_rpg.htm acessado em 09/08/02). Usa-se 1974 como a data origem do RPG por aparecer na maioria das obras.

[3] Já está no mercado a terceira edição do Dungeon \& Dragons, o Neverwinter, da Biowave. A versão é para PC e conta com mais de 60 horas de jogo, em que o jogador pode "guiar bárbaros, ladrões e magos para banir as forças do mal" (Revista Superinteressante, edição 179, agosto de 2002, p:82).

[4] A página http://www.jornalopcao.com.br/informatica.asp?secao=Inform\%C3\%A1tica\&idjornal=48 traz informações de como jogar RPG por e-mail.

[5] Tradução livre de: Role play is one of a whole gamut of communicative techniques which develops 
fluency in language students, which promotes interaction in the classroom, and which increases motivation.

[6] Nesta segunda semana de agosto de 2002, a Revista Veja (adição 1763, ano 35, n⿳0 31, de 7 de agosto de 2002, p:133) traz o livro Quem mexeu no meu queijo? na $86^{\mathrm{a}}$ semana entre os dez livros mais vendidos do Brasil.

[7] As transcrições são fiéis aos textos escritos pelos acadêmicos, portanto, ocorrem erros e problemas com a clareza dos escritos. 